any other faith can belong to it, and they do in fact contribute to its thinking and activities. Members of the Institute have already set up two special commissions, one to study the education of both the medical and clerical professions, and the other the problems of mental health. Contact has been made with many local groups of clergy and doctors that were already in existence, and new ones have been formed. The rapidity with which this arganization has got going despite slender financial resources clearly shows that it is welcome and has valuable work to do.

Both doctors and ministers of religion feel that their status and roles in our society are under critical scrutiny. Scientific advances, while producing revolutions in the care of illness, have thereby created new problems in the place of old ones that may seem to be settled. For example, decisions about life and death are perhaps more complicated than they were, and there is much confusion and misunderstanding about the best ways to help young people over sexual and marital problems. Moreover, social workers of all sorts are now taking over some of the roles formerly filled by doctors and clergy. The time is ripe for a reappraisal of all this work, and the studies already initiated by the Institute show that its members are prepared for some fresh thinking as well as dealing with day-to-day problems of human beings who may also be patients and parishioners.

Similar organizations have been in existence in America and elsewhere for some years. All men have to face the problems of pain, mental suffering, illness, misery, and death, but traditional ideas on how best to support them in these predicaments are changing. Hence the need for a meetingpoint such as the Institute sets out to provide.

\section{Thyrotoxicosis in Children}

It is disappointing that in an important follow-up study recently reported T. McKendrick and G. H. Newns ${ }^{1}$ found that in 10 out of 33 children with thyrotoxicosis the interval between the onset of symptoms and diagnosis had exceeded one year. The possibility of the disease occurring in childhood therefore needs to be borne in mind. Indeed, there is hardly a disease of adults which does not also, however rarely, attack children. Moreover, as these authors point out, the early symptoms are usually difficult, if not impossible, to distinguish from those of an emotional disturbance. And this itself may have a role in the aetiology of thyrotoxicosis, which is still obscure but likely to comprise a variety of causes. Thus K. M. Saxena, J. D. Crawford, and N. B. Talbot ${ }^{2}$ in another recent long-term study of childhood thyrotoxicosis suggest that there was an emotional precipitant in one-third of their patients.

Thyrotoxicosis is uncommon during the first 10 years of life, and congenital thyrotoxicosis, of which an instance has been reported recently by $\mathrm{Z}$. H. Zaidi, ${ }^{3}$ is exceedingly rare, occurring only in infants of mothers who have been treated for thyrotoxicosis. In later childhood and adolescence the condition becomes more frequent. The diagnosis is usually

\footnotetext{
1 McKendrick, T., and Newns, G. H., Arch. Dis. Childh., 1965, 40, 71. Saxena, K. M., Crawford, J. D., and Talbot, N. B., Brit. med. F., 1964 , 2,1153 .

- Zaidi, Z. H., Proc. roy. Soc. Med., 1965, 58, 390.

- Brit. med. F., 1964, 2, 1147.

W Wilkins, L., in Pediatrics, ed. L. E. Holt, R. McIntosh, and H. L. Barnett, 13th ed., p. 679. New York. 1962.
}

easy and in most cases can be confidently made on clinical grounds. When there is doubt, estimation of the serum protein-bound iodine is the most useful investigation.

The onset of the condition is frequently associated with an abnormally rapid gain in height. In the fully developed case the classical signs as they are found in adults are present, but with one important proviso : the fine tremor is less common and the involuntary movements tend to consist of a coarse tremor and choreiform jerks. These children may therefore be referred to hospital with an incorrect diagnosis of chorea.

At present the ideal treatment does not exist, and therefore, not surprisingly, there is no agreement on the management of these children. Though mortality from partial thyroidectomy is very low, relapse or hypothyroidism may follow the operation. Nevertheless, Professor Talbot and his colleagues ${ }^{2}$ prefer surgical to medical treatment with antithyroid drugs, but on the basis of their experiences suggest that radioiodine treatment under careful supervision deserves further study. A preference for trying drug treatment before resorting to surgery has also been advocated, with cautionary advice against radioiodine because of the high incidence of latedeveloping hypothyroidism in adults thus treated. ${ }^{4}$ Similarly, McKendrick and Newns recommend that surgery be delayed wherever possible until after puberty, and most paediatricians would agree.

The most widely used antithyroid drugs are methylthiouracil, propylthiouracil, carbimazole, and sodium (or potassium) perchlorate. The most serious, but fortunately rare, reaction to these drugs is agranulocytosis; others are fever, pruritus, urticaria, gastro-intestinal disturbances, headache, and joint pains and swellings. There are at present insufficient data on which to base a recommendation for any particular one of these four antithyroid agents ; carbimazole is favoured by many, including McKendrick and Newns. They recommend that drug therapy should be given for two years and then stopped. About one-third of their patients relapsed after treatment had been discontinued, and with one exception this relapse occurred within a year of stopping treatment. In cases of relapse the authors recommend a second two-year course of medical treatment before resorting to surgery. Serious drug reactions and lack of co-operation may interfere with such a long trial. According to the late Lawson Wilkins, ${ }^{5}$ whose experience of the condition must have been second to none, a permanent remission may be expected in $50-75 \%$ of children with thyrotoxicosis treated medically.

\section{Iris Pigmentation and Mydriatics}

It is common clinical experience in ophthalmology that a heavily pigmented iris will not dilate with mydriatic drops as effectively as a light-coloured iris. The failure of deeply pigmented irides to dilate is most apparent with the sympathomimetic (adrenergic) mydriatics such as adrenaline, ephedrine, and phenylephrine. This comparative lack of response to mydriatics has been attributed to a racial difference, probably structurally determined, ${ }^{1}$ and a recent paper by $H$. $O$.

\footnotetext{
Duke-Elder, S., System of Ophthalmology, 1962, Vol. VII, p. 482.

= Obianwu, H. O., and Rand, M. J., Brit. F. Ophthal., 1965, 49, 264.
} 